\title{
Editorial
}

\section{Migration and transhumance: thank you Brussels!}

In recent months, the numerus clausus ("ceiling number") in PACES (Première Année Commune aux Etudes de Santé) has become a subject of major concern. For the President of the Republic, it is "an unfair and ineffective system" that must be eradicated by 2020; although, it is unclear how this should be conducted, because it is not a question about abandoning any principle of regulation. The numerus clausus would be replaced by the numerus apertus ("floor number"), which each university will be able to decide upon based on their local environment. At the same time, the notion of "receipt and paste" for students who will have more than $10 / 20$ but who would not have a "useful" rank, as well as the prohibition to repeat grades in case of poor ones is emerging. The text is due to be presented to Parliament in March 2019, when PACES will be replaced by the Health Portal. Coincidently, the numerus clausus in PACES was also addressed in the film by Thomas Lilti, Premiere année [First year], which was released on September 12, 2018. As a result, the selection method that has been in use for almost 50 years has finally been made public. It is doubtful that this reform will completely eliminate this "unfair and inefficient" selection method because the number of places will not increase significantly; and, it is likely that the joke found in the movie trailer for First Year will still be relevant: "do you know the difference between a medical student and a prep student? Ask them to learn the directory by heart. The prep student will ask: why? The medical student will ask: for when?"

The numerus clausus was established in 1971 at the request of certain medical unions, with the support of the Conseil de l'Ordre [Counsel Order], which called for a selective competition to limit the numbers of medical students at the end of the first year due to the sudden increase in the numbers: 35,000 in 1963 , followed by 60,000 in 1967 . The government agreed because it saw this as a hidden means of limiting healthcare expenditures. However, we can now clearly see the disadvantageous effects of this numerus clausus, which no longer fulfills its original purpose. Nearly one-fifth of the new doctors who in work in France each year, approximately 1,600, have a degree from a foreign university. For example, at Pierre-Bérégovoy Hospital in Nevers, 55\% of the 143 practitioners were born and graduated outside of France! Moreover, with free movement within the EU, the numerus clausus has become an object of ridicule. In 2017, there were nearly 60,000 candidates in PACES; 13,500 got through but only 8,200 in medicine and 1,199 in dental surgery, amounting to a total of just over $15 \%$ of participants. Furthermore, in 2017, there were 42,821 dental surgeons in France $(40,191$ general practitioners, 2,410 DF0 specialists, 152 oral surgeons, and 68 MBD specialists): 39,593 were French practitioners, 2,627 were from within the EU, and 598 from a non-EU country; the latter two, either the 3,225 practitioners, were practicing in France without ever facing the horrors of numerus clausus. Out of the 1,673 first-time registration into Counsel Order in 2017, there were 1,300 French, 156 Romanians, 72 Portuguese, 65 Spaniards, and 18 Italians; out of 260 first-time French enrollments trained abroad, 101 had studied in Spain, 81 in Romania, 37 in Portugal, and 31 in Belgium... In total, $37 \%$ of first-time registrations into Counsel Order had graduated from outside of France, thereby escaping the numerus clausus. Faced with these figures, one may wonder if the numerus clausus has not become a charade?

In Switzerland, the numerus clausus has appeared only recently and is not yet as brutal as the French numerus clausus. It is either applied before enter university - in the form of aptitude tests-or at the end of the first year. In 2002, Switzerland signed Bilateral Agreements with the EU and from June 1, 2002, it scrupulously applied the legislation on the equivalence of degrees and qualifications. Since 2002, Switzerland has recognized an average of 355 foreign qualifications each year, whereas it has only awarded 109 federal degrees (i.e., obtained in Switzerland); this number has been constant for almost three decades. As of December 31, 2017, there were 6,031 dentists practicing in Switzerland: 1,683 practitioners had obtained a federal diploma and 5,428 had obtained an equivalent degree. Out of these, in $2014,73.7 \%$ had graduated from a border country (42.7\% in Germany, $16.7 \%$ in France, and $14.3 \%$ in Italy). In 2017, out of the 524 dentists licensed to practice, $62.8 \%$ held a recognized foreign diploma (compared to $60.7 \%$ in 2016). Some foreign practitioners have returned to their home countries, but since migration largely outweighs transhumance, there is currently a plethora of dentists in Switzerland. Almost half of all practices are empty at least one day a week and there have already been several bankruptcies. The Swiss Society of Odontostomatology has tried to alert the Swiss federal authorities by demanding, among other things, effective control of the value of diplomas. The last time, they quoted the thesis of Marco Mazevet, "Evaluation of clinical practice in the curriculum of studies in dentistry in the European Union," University of Rennes 2016. It reveals that about $10 \%$ of European students can graduate without ever having undergone any practical 
experience. The response of the authorities was technocratic: “This study does not rely on a systematic analysis of training provisions or on training actually provided." They have probably not carefully read the thesis and pretend to ignore, like many others, the Romanian degree mill, mainly that of the University of Cluj-Napoca (there are two other Universities in Romania who provide education in French for health professions), where repetition is exceptional because, after a failure, you are entitled to another attempt or even a third one! Since its entry into the EU in 2007, Romania has flooded some European countries: in France, the number of doctors graduated in Romania has increased sevenfold in 10 years; this number was 4,254 as of January 1,2017 . If one really wanted to appreciate the value of the training, one could, for example, announce at which Universite of origin of the candidates for the national ranking test for doctors. However, the origin of the candidates remains confidential and the names of the universities of origin are only available for the 10 lowest ranked; in 2015, five had studied in Romania, three in Italy, and one in Spain.

All these figures probably giving you a headache, but they are relevant to display the absurdity of the situation that results from the automatic equivalence of diplomas, both in France and in Switzerland. In France, thousands of students in PACES and hundreds in Switzerland were impeded when they could have been admitted if the numerus clausus had been adapted to real needs. Some will argue that there are not enough facilities to increase the numerus clausus and ensure proper training. Under the pretext of privileging training, they intend to keep the numerus clausus in its present form. They may be unaware that in the 1960s, when there were fewer hospitals and doctors installed, up to 12,000 physicians were trained each year, and now there are more by simulation, massive open online courses... The French and Swiss leaders are satisfied with the situation because graduates trained abroad do not cost the government anything and they are ready to shamelessly continue exploiting this sector. It is even better when, after training that has cost nothing, we can compel the practitioner to work in public hospitals under unfair conditions; there are about 4,000 foreign doctors (non-EU) working in France as interns or associate practitioners. In Switzerland as well there are many doctors with a foreign diploma who are working in public hospitals, but they have the same status as native people; however, they are often left behind during promotions.

Finally, a last perverse effect of the automatic recognition of diplomas is that two striking trials have occurred in the last two years. In 2016, a Dutch dentist already sanctioned in his country was sentenced by the Criminal Court of Nevers to eight years in prison; in 2018, a Romanian dentist was sentenced by the Angoulême Criminal Court to heavy fines and suspended sentence of 3 years in prison. These two individuals were also permanently banned from medical practice.

Will the authorities finally become aware of the situation and stop focusing solely on medical deserts? Will they stop having a timid attitude and put an end to this system? The European directives sometimes have a perverse effect: we had a Polish plumber, could we avoid having a Romanian doctor or dentist? Normally, these guidelines do not establish automatic equivalence, since "the student or the migrant worker may be subject to compensation measures in the event of a substantial difference between their training." However, doctors and dentists (such as nurses, midwives, veterinarians, pharmacists, and architects) are covered by a sectoral directive and they "benefit" from automatic recognition. Without wishing to put an end to all migration - of which I was one of the beneficiaries a long time ago-it would probably be a good idea to analyze the situation with pragmatism and take appropriate measures to stop penalizing the students who wish to go into the healthcare professions.

Jacky Samson*

Faculty of Medicine of Geneva, Avenue Louis-Casaï 27, 1209 Geneva,

Switzerland

*Corresponding author: jacky.samson74@gmail.com 